\title{
To Pee or Not to Pee: No More the Question in ARF?
}

See Liangos et al., pp. c56-c60

\author{
R. Vanholder W. Van Biesen N. Lameire \\ Department of Internal Medicine, Nephrology Section, 0K12, University Hospital, Gent, Belgium
}

Acute renal failure (ARF) frequently complicates the course of patients with severe comorbidities, and increases their mortality, length of hospital stay, and hospitalization costs. Removal by dialysis of the retained waste products remains one of the therapeutic cornerstones for severe ARF. Several of these compounds, especially potassium and water, have a direct impact on mortality.

Guidelines about when to start dialysis in case of ARF are, however, not available. Treating physicians are most currently guided by biochemical alarm signs, such as hyperkalemia, acidosis and uremia, or clinical alarm signs such as fluid overload and oliguria, currently defined as a urinary volume $<400 \mathrm{ml} /$ day. Up to $80 \%$ of cases of ARF, however, show a maintained urinary flow [1], hence making urinary volume a less reliable indicator.

The impact of this unreliability on therapeutic decision-making and subsequent outcome is analyzed in the current issue of Nephron Clinical Practice by Liangos et al. [2]. Their most striking finding is that a higher urinary volume at first nephrologic consultation is related to a worse outcome. Such a link has, to the best of our knowledge, not yet been demonstrated. Older analyses even pointed to a lower mortality in non-oliguric $\operatorname{ARF}[1,3]$, but had, in contrast to the study under discussion, been undertaken in populations of which $50 \%$ did not require subsequent dialysis, and had not been corrected for confounders.

The observation by Liangos et al. [2] is opposite to the current belief that maintained diuresis is beneficial, an opinion based on at least three assumptions that a higher urinary volume: (1) is automatically linked to better kidney function and less retention of uremic products; (2) protects against fluid overload, and (3) should allow the administration of higher amounts of calorie-loaded infusions, hence preventing malnutrition and its complications.

It is challenging to conceive reasons for the unexpected opposite finding by Liangos et al. [2]. The most logical explanation is that dialysis treatment and perhaps also nephrological consultation are postponed, due to an unwarranted feeling of safety. Mehta et al. [4] demonstrated a direct link between timeliness of nephrologic consultation and patient outcome. In the study by Liangos et al. [2], a positive correlation was found between urinary volume and the moment to start dialysis.

There are several drawbacks to this study. This observational post-hoc analysis, in a relatively small group of patients, was limited to a subpopulation of intensive care patients, later on to be enrolled to intermittent hemodialysis. The data should be confirmed in studies with a prospective design, and in larger patient populations preferably spread over multiple units in different countries and with different therapeutic attitudes.

The selection of patients subsequently to be treated by intermittent hemodialysis is a handicap, decreasing the number of patients and limiting them to a specific subpopulation. One could argue that there are no evidencebased arguments supporting this decision: in none of the

\section{KARGER \\ Fax +4161306 1234 E-Mail karger@karger.ch} www.karger.com
(C) 2005 S. Karger AG, Basel $1660-2110 / 05 / 0992-0061 \$ 22.00 / 0$

Accessible online at: www.karger.com/nec
Raymond Vanholder

Nephrology Section, Department of Internal Medicine, 0K12, University Hospital De Pintelaan 185

BE-9000 Gent (Belgium)

Tel. +32 9 2404522, Fax +3292404599, E-Mail raymond.vanholder@ugent.be 
controlled randomized studies undertaken until now, as well as in a recent meta-analysis [5], was the outcome between patients treated on intermittent versus continuous dialysis strategies different.

On the other hand, however, in clinical reality out of study context, continuous dialysis strategies are especially applied in hemodynamically unstable patients with a bleak prognosis. The possibility should be considered that these problems could overrule a potential relationship of urinary volume with outcome, hence skewing the results. Therefore, excluding patients needing continuous therapy is a defendable decision.

It is impossible to appreciate from this study the impact of therapeutic use of diuretics on urinary volume and outcome. In a recent study, Mehta et al. [6] quite surprisingly demonstrated a negative impact of the administration of diuretics on outcome of ARF. It was suggested that converting ARF into a non-oliguric form might have delayed its recognition [6]. Of note, however, poor results were more frequent in patients not responding to diuretic challenge [7]. In the study by Liangos et al., use of diuretics or not was not included as a study parameter, al- though diuretics were conceivably administered to a large proportion of the patients. Hence, whether the link between outcome and urinary volume is due to their relationship per se, or to use of diuretics as an interfering factor, remains unresolved by this study.

In spite of its limitations, the study underscores four important issues: (1) maintained urinary production is no safeguard to withhold dialysis treatment from ARF patients; (2) the same attitude on starting dialysis should be applied both in non-oliguric and oliguric ARF patients; (3) the follow-up of patients at potential risk for ARF should not be focused on urinary volume, but concentrate on objective markers of renal function, and (4) there is an urgent need for guidelines when to start dialysis treatment in ARF.

Although this was not the issue of the study, the data also indirectly argues in favor of a timely consultation of the nephrologist on intensive care, who will be helpful in the correct interpretation of renal function parameters and may, if needed, accelerate the decision to start dialysis.

\section{References}

$\checkmark 1$ Hou SH, Bushinsky DA, Wish JB, Cohen JJ, Harrington JT: Hospital-acquired renal insufficiency: A prospective study. Am J Med 1983; 74:243-248.

-2 Liangos O, Rao M, Balakrishnan VS, Pereira BJG, Jaber BL: Relationship of urine output to dialysis initiation and mortality in acute renal failure. Nephron Clin Pract 2005;99:c56-c60.
3 Anderson RJ, Linas SL, Berns AS, Henrich WL, Miller TR, Gabow PA, Schrier RW: Nonoliguric acute renal failure. N Engl J Med 1977; 296:1134-1138.

-4 Mehta RL, McDonald B, Gabbai F, Pahl M, Farkas A, Pascual MT, Zhuang S, Kaplan RM, Chertow GM: Nephrology consultation in acute renal failure: Does timing matter? Am J Med 2002;113:456-461.

>5 Tonelli M, Manns B, Feller-Kopman D: Acute renal failure in the intensive care unit: A systematic review of the impact of dialytic modality on mortality and renal recovery. Am J Kidney Dis 2002;40:875-885.
-6 Mehta RL, Pascual MT, Soroko S, Chertow GM: Diuretics, mortality, and nonrecovery of renal function in acute renal failure. JAMA 2002;288:2547-2553.

7 Lameire N, Vanholder R, Van Biesen W: Loop diuretics for patients with acute renal failure: Helpful or harmful? JAMA 2002;288:2599_ 2601. 